\title{
Prone position and recruitment manoeuvre: the combined effect improves oxygenation
}

\author{
Gilles Rival ${ }^{1 *}$, Cyrille Patry², Nathalie Floret ${ }^{3}$, Jean Christophe Navellou², Evelyne Belle ${ }^{2}$ and Gilles Capellier ${ }^{2,4}$
}

\begin{abstract}
Introduction: Among the various methods for improving oxygenation while decreasing the risk of ventilationinduced lung injury in patients with acute respiratory distress syndrome (ARDS), a ventilation strategy combining prone position (PP) and recruitment manoeuvres (RMs) can be practiced. We studied the effects on oxygenation of both RM and PP applied in early ARDS patients.

Methods: We conducted a prospective study. Sixteen consecutive patients with early ARDS fulfilling our criteria (ratio of arterial oxygen partial pressure to fraction of inspired oxygen $\left(\mathrm{PaO}_{2} / \mathrm{FiO}_{2}\right) 98.3 \pm 28$ mmHg; positive end expiratory pressure, $10.7 \pm 2.8 \mathrm{cmH}_{2} \mathrm{O}$ ) were analysed. Each patient was ventilated in both the supine position (SP) and the PP (six hours in each position). A $45 \mathrm{cmH}_{2} \mathrm{O}$ extended sigh in pressure control mode was performed at the beginning of SP (RM1), one hour after turning to the PP (RM2) and at the end of the six-hour PP period (RM3).

Results: The mean arterial oxygen partial pressure $\left(\mathrm{PaO}_{2}\right)$ changes after $\mathrm{RM} 1, \mathrm{RM} 2$ and $\mathrm{RM} 3$ were 9.6\%, 15\% and $19 \%$, respectively. The $\mathrm{PaO}_{2}$ improvement after a single RM was significant after $\mathrm{RM} 3$ only $(P<0.05)$. Improvements in $\mathrm{PaO}_{2}$ level and $\mathrm{PaO}_{2} / \mathrm{FiO}_{2}$ ratio were transient in SP but durable during $\mathrm{PP}$. $\mathrm{PaO}_{2} / \mathrm{FiO}_{2}$ ratio peaked at $218 \mathrm{mmHg}$ after $\mathrm{RM} 3 . \mathrm{PaO}_{2} / \mathrm{FiO}_{2}$ changes were significant only after $\mathrm{RM} 3$ and in the pulmonary ARDS group $(P=0.008)$. This global strategy had a benefit with regard to oxygenation: $\mathrm{PaO}_{2} / \mathrm{FiO}_{2}$ ratio increased from $98.3 \mathrm{mmHg}$ to 165.6 $\mathrm{mmHg} 13$ hours later at the end of the study $(P<0.05)$. Plateau airway pressures decreased after each RM and over the entire PP period and significantly after RM3 $(P=0.02)$. Some reversible side effects such as significant blood arterial pressure variations were found when extended sighs were performed.

Conclusions: In our study, interventions such as a $45 \mathrm{cmH}_{2} \mathrm{O}$ extended sigh during PP resulted in marked oxygenation improvement. Combined RM and PP led to the highest increase in $\mathrm{PaO}_{2} / \mathrm{FiO}_{2}$ ratio without major clinical side effects.
\end{abstract}

\section{Introduction}

Acute respiratory failure is a common pathology in intensive care units. Management of acute respiratory distress syndrome (ARDS) and acute lung injury (ALI) [1] remains a problem. Life care support such as mechanical ventilation is used to maintain or improve oxygenation. Nevertheless, as is true of many therapies, side effects such as ventilation-induced lung injury (VILI) and oxygen toxicity have been described $[2,3]$. Moreover, increased mortality in ARDS patients is well established when patients are ventilated with high tidal volume $\left(V_{\mathrm{t}}\right)$ and high plateau pressure. Nowadays, low

\footnotetext{
* Correspondence: gilles.rival@yahoo.fr

'Service de pneumologie, Centre Hospitalier Régional et Universitaire de Besançon, 3 Bd Fleming, Besançon F-25000, France

Full list of author information is available at the end of the article
}

$V_{\mathrm{t}}$ and limited plateau pressure below $30 \mathrm{cmH}_{2} \mathrm{O}$ have been associated with lower mortality and less inflammation [4-6]. Mechanical ventilation is therefore recommended as a lung-protective strategy. However, such ventilator settings are reported to induce hypoxemia, hypercapnia, alveolar derecruitment and atelectasis, which also contribute to lung injury $[7,8]$. Inflated, normal, poorly aerated or nonaerated airway spaces coexist, and ventilation may induce (1) shear stress at the boundaries of these spaces, (2) inadequate cyclic opening and (3) closing of alveoli. Inflammation as well as cellular and epithelial damage may be associated with this type of ventilation $[9,10]$. The "open lung concept" was developed to fight against these ventilatory side effects and to improve oxygenation [11-16]. Opening pressures used should recruit poorly aerated or

\section{Biomed Central}


nonaerated airway spaces, and once this procedure is carried out, positive end expiratory pressure (PEEP) can be applied to stabilize cyclic opening and closing of alveoli to decrease VILI and to maintain oxygenation improvement [17-21]. To reinforce this strategy, an animal study suggested that a low stretch/open lung strategy compared to a low stretch/rest lung strategy was associated with lower mortality, decreased inflammatory response, more apoptosis and less epithelial damage [22]. Prone position (PP) [23-26] and recruitment manoeuvre (RM) [27-36] have been studied, and some benefit on alveolar recruitment, VILI and oxygenation has been demonstrated [37]. In daily practice and from a practical point of view, lung-protective ventilation is recommended. In addition to this strategy, RM can be performed while patients are in supine position (SP), and they can be turned to PP if hypoxemia remains a concern. In the present study, we tested the hypothesis that RM might have a different impact on oxygenation according to whether it was performed with patient in SP or in early or late PP. We therefore conducted a prospective study to evaluate the benefits of extended sigh using $45 \mathrm{cmH}_{2} \mathrm{O}$ airway pressure combined with PP in acute respiratory failure.

\section{Materials and methods Population}

From June 2002 to March 2003, we prospectively studied, during the first week of ventilation, patients with ARDS or ALI, defined according to the criteria of the ARDS American European Consensus Conference [1]. This study was approved by our local hospital ethics committee (Comité d'éthique clinique du CHU de Besançon). Written informed consent was waived. Patients were sedated, paralysed and ventilated in the volume control mode. Vasopressive drugs and fluid resuscitation were used as required to obtain a mean arterial pressure (MAP) of $75 \mathrm{mmHg}$. Patients with uncontrolled low cardiac output, a temporary pacemaker, bronchospasm or barotrauma were excluded.

\section{Basic ventilation}

A lung-protective ventilation strategy was used to maintain plateau pressure below $30 \mathrm{cmH}_{2} \mathrm{O}$ [20]. PEEP was adjusted to obtain $92 \% \pm 2 \%$ oxygen saturation measured via pulse oximetry $\left(\mathrm{SpO}_{2}\right)$ with fraction of inspired oxygen $\left(\mathrm{FiO}_{2}\right)$ between $60 \%$ and $80 \%$. PEEP may have been increased to $6,8,10,12$ or $14 \mathrm{cmH}_{2} \mathrm{O}$ to achieve the above criteria. Once these $\mathrm{FiO}_{2}$ and $\mathrm{SpO}_{2}$ criteria had been reached, ventilatory parameters were not changed. If $\mathrm{FiO}_{2}$ was still higher than $80 \%$ with a PEEP of $14 \mathrm{cmH}_{2} \mathrm{O}$, the increase in PEEP was interrupted and the patient was included in the study at that time. The inspiratory/expiratory (I/E) ratio was adjusted between
1:2 and 1:3. Basic ventilation was used, except when RM was performed. Mount connections were systematically removed. Heat humidifiers were used.

\section{Recruitment manoeuvre}

The RM consisted of changing the ventilatory mode to the pressure control mode and increasing pressure levels every 30 seconds to successively obtain 35,40 and 45 $\mathrm{cmH}_{2} \mathrm{O}$ peak inspiratory pressures (PIP) (Figure 1). Once the $45 \mathrm{cmH}_{2} \mathrm{O}$ PIP had been reached, a 30-second end-inspiratory pause was performed using the inspiratory pause function. The I/E ratio was maintained at 1:1 during RM. Respiratory frequency, PEEP and $\mathrm{FiO}_{2}$ were similar during RM. We returned to basic ventilation every 30 seconds throughout the various 30 -second steps described above. At the end of the RM, previous ventilatory adjustments were applied.

\section{Prone position}

PP was maintained for six hours. $\mathrm{FiO}_{2}$ may have been temporarily increased to $100 \%$ while the patient was turned, and then it decreased back to the initial $\mathrm{FiO}_{2}$ level.

\section{Protocol}

Two six-hour periods were used: one with patient in SP and one in PP. The first RM was performed at the beginning of SP (one hour after stabilization), the second one was performed one hour after turning the patient to PP and the last one was performed at the end of PP (Figure 2). Ventilatory settings, gas exchanges and haemodynamic parameters were recorded each time (from time 0 to time 8) in SP and PP: at the time of inclusion, before and immediately after each RM, before PP and one hour after turning the patient to SP.

\section{Statistical methods}

For this descriptive and analytical study, nonparametric tests were used. The Wilcoxon paired test was carried out to compare the variables before and after recruitment manoeuvres. If the number of equal variables was high, a sign test was implemented. The quantitative variables studied are reported in the tables as means \pm standard deviations. A $P$ value $<0.05$ was considered statistically significant. The different analyses were carried out by using SYSTAT 8.0 software.

\section{Results}

\section{Population}

Table 1 shows the patient demographics. Sixteen ARDS patients were prospectively included, 12 with pulmonary ARDS and four with extrapulmonary ARDS. Thirteen patients completed the study, while for three patients the protocol was interrupted at some point. Pneumonia 


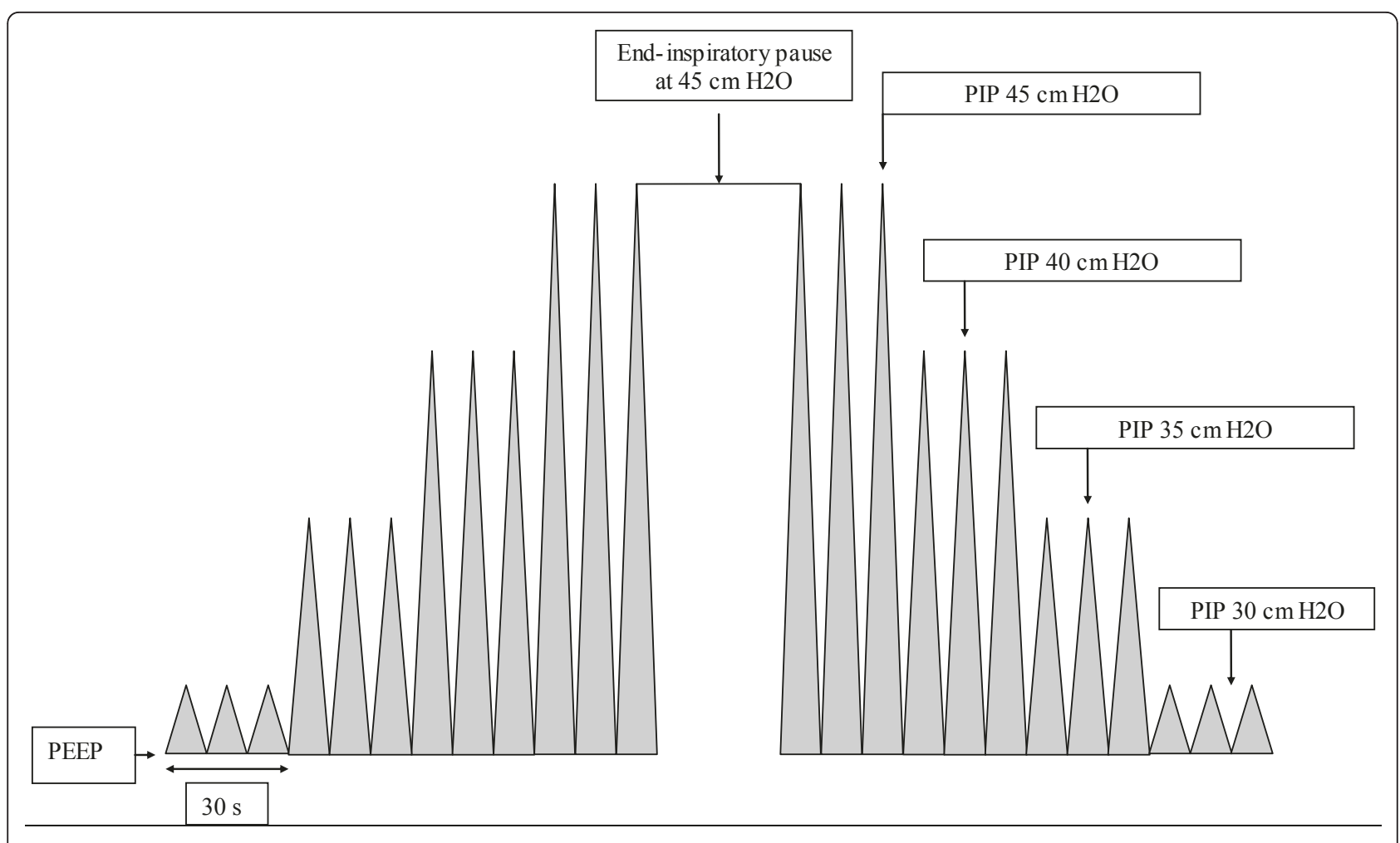

Figure 1 Recruitment maneuver in pressure control mode ventilation

and pancreatitis were the main causes of ARDS. The patients were 63 years old on average. The mean Simplified Acute Physiology Score II was 44.7. The mean number of organ failures was about two. The mortality rate was $43.7 \%$. Seven patients died, five as a result of pulmonary ARDS and two as a result of extrapulmonary ARDS.

\section{Ventilatory settings}

Table 2 shows the ventilator settings maintained throughout the whole study and their different effects on peak and plateau airway pressure. These decreased after each RM and over the entire PP period. The decrease in plateau pressure was significant after RM3 $(P=0.02)$. Plateau pressures at time 8 were lower than T0, but the decrease was not statistically significant.

\section{Gas exchange}

Table 3 shows the effects of gas exchange.

\section{Impact of RM on gas exchange}

$\mathrm{PaO}_{2}$ and $\mathrm{PaO}_{2} / \mathrm{FiO}_{2}$ ratio increased after each $\mathrm{RM}$. The mean $\mathrm{PaO}_{2}$ changes before and after RM1, RM2 and RM3 were $9.6 \%, 15 \%$ and $19 \%$, respectively. The $\mathrm{PaO}_{2} /$ $\mathrm{FiO}_{2}$ ratio peaked at $218 \mathrm{mmHg}$ after $\mathrm{RM}$. The

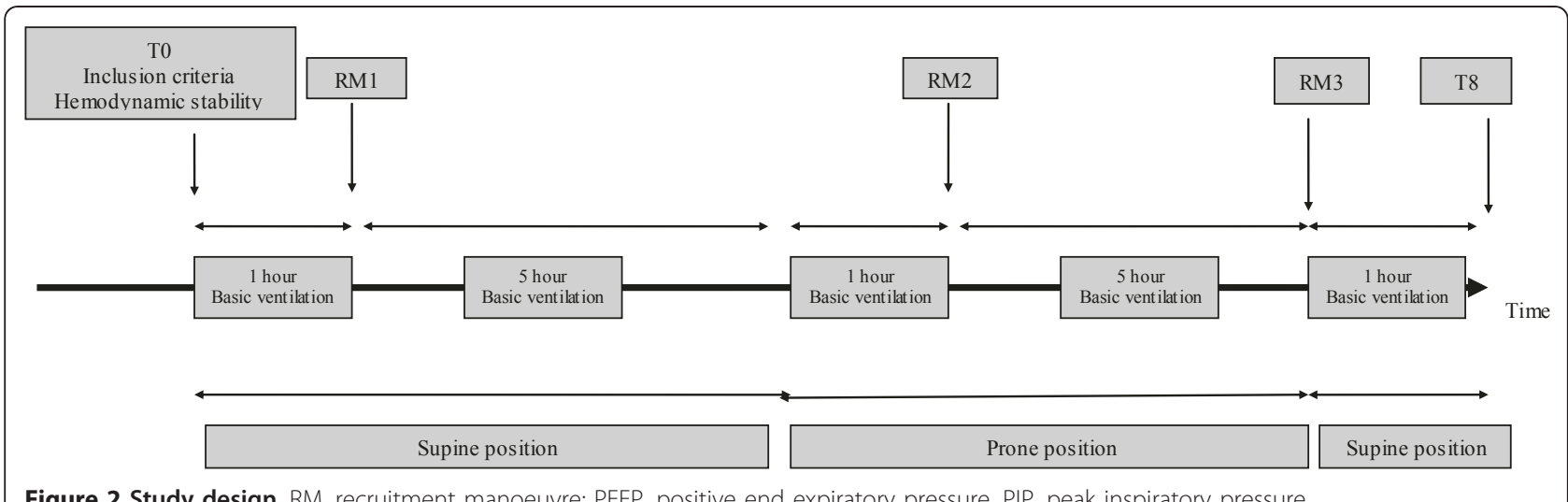

Figure 2 Study design. RM, recruitment manoeuvre; PEEP, positive end expiratory pressure, PIP, peak inspiratory pressure. 
Table 1 Patient population ${ }^{\mathrm{a}}$

\begin{tabular}{lcc}
\hline Patient demographics & $\begin{array}{c}\text { Pulmonary } \\
\text { ARDS }\end{array}$ & $\begin{array}{c}\text { Extrapulmonary } \\
\text { ARDS }\end{array}$ \\
\hline Number of patients & 12 & 4 \\
Average age, years & 63 & 66 \\
SAPS II & 47 & 39 \\
Organ failure & 2.5 & 1.75 \\
$\mathrm{PaO}_{2} / \mathrm{FiO}_{2}$ ratio at time 0, & 99 & 97.5 \\
$\mathrm{mmHg}^{\text {Deaths, } n}$ & & 2 \\
Diagnosis, $n$ & 5 & \\
$\quad$ Pneumonia & & \\
$\quad$ Aspiration & & \\
$\quad$ Acute pancreatitis & 9 & 4
\end{tabular}

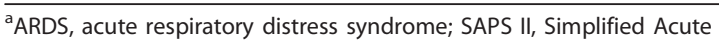
Physiology Score II; $\mathrm{PaO}_{2} / \mathrm{FiO}_{2}$ ratio, ratio of arterial oxygen partial pressure to fraction of inspired oxygen. ${ }^{b}$ Organ Dysfunction and/or Infection score was used to quantify the number of organ failures.

improvement before and after a single RM was significant after RM3 only $(P<0.05)$. Arterial carbon dioxide partial pressure $\left(\mathrm{PaCO}_{2}\right)$ decreased after each $\mathrm{RM}$ $(P<0.05)$.

Impact of RM on gas exchange depending on body position Improvements in $\mathrm{PaO}_{2}$ and $\mathrm{PaO}_{2} / \mathrm{FiO}_{2}$ ratio were transient in SP but durable during PP between RM2 and RM3. The decrease in $\mathrm{PaCO}_{2}$ after RM1 was transient in SP and durable in PP.

\section{Impact of the global strategy on gas exchange}

When patients were included, the $\mathrm{PaO}_{2} / \mathrm{FiO}_{2}$ ratio was $98.3 \mathrm{mmHg}$ with $79 \% \mathrm{FiO}_{2}$ and $10 \mathrm{cmH}_{2} \mathrm{O}$ PEEP. At the end of the study, in SP and compared to the beginning, the $\mathrm{PaO}_{2} / \mathrm{FiO}_{2}$ ratio was significantly higher at $165.6 \mathrm{mmHg}(P<0.05) . \mathrm{PaCO}_{2}$ decreased from 39 $\mathrm{mmHg}$ at the beginning of the study to $36.4 \mathrm{mmHg}$ at the end of the study.

\section{Impact of RM on gas exchange depending on} extrapulmonary or pulmonary ARDS

In the pulmonary ARDS group, the $\mathrm{PaO}_{2} / \mathrm{FiO}_{2}$ ratio improved from $115 \pm 47 \mathrm{mmHg}$ to $128 \pm 59 \mathrm{mmHg}$ after RM1, from $162 \pm 83 \mathrm{mmHg}$ to $196 \pm 104 \mathrm{mmHg}$ after RM2 and from $185 \pm 83 \mathrm{mmHg}$ to $230 \pm 101$ $\mathrm{mmHg}$ after RM3. In patients with extrapulmonary ARDS, the $\mathrm{PaO}_{2} / \mathrm{FiO}_{2}$ ratio improved from $102 \pm 19$ $\mathrm{mmHg}$ to $107 \pm 22 \mathrm{mmHg}$ after RM1, from $113 \pm 12$ $\mathrm{mmHg}$ to $112 \pm 35 \mathrm{mmHg}$ after RM2 and from $149 \pm$ $23 \mathrm{mmHg}$ to $154 \pm 78 \mathrm{mmHg}$ after RM3. In these subgroups, changes in $\mathrm{PaO}_{2} / \mathrm{FiO}_{2}$ ratio were significant only after RM3 and only in the pulmonary ARDS group $(P=0.008)$.

\section{Haemodynamics}

Figure 3 shows the haemodynamic effects. Vasopressive drug infusion rates were not modified throughout the entire study. A significant decrease in MAP was found when extended sighs were performed. However, they were reversible when the manoeuvre was stopped.

\section{Complications}

One patient had reversible bronchoconstriction after an extended sigh. PP could not be performed in a second patient because of heart rate disorders. PP had to be interrupted in the first few minutes for a third patient because of major desaturation related to an increase in airway pressure (above $50 \mathrm{cmH}_{2} \mathrm{O}$ ) due to abdominal compartment syndrome. RM did not cause pulmonary barotrauma. Predominant dermabrasions on the chest and the abdomen as well as facial oedema were observed after PP in four patients.

\section{Discussion}

The main findings of our early ARDS/ALI study are that there are probable combined effects of RM and PP as well as a larger $\mathrm{PaO}_{2}$ improvement when RM is performed while the patient is in PP and probably after an extended period of time.

RMs have been proved to be efficient to protect the lung while improving oxygenation $[37,38]$; however, a computed tomography-based study performed during

Table 2 Ventilatory settings used during the study ${ }^{a}$

\begin{tabular}{|c|c|c|c|c|c|c|c|c|c|}
\hline \multirow{3}{*}{$\frac{\text { Ventilatory setting }}{V_{\mathrm{t}} \mathrm{mL}}$} & \multicolumn{4}{|c|}{ SP } & \multicolumn{4}{|c|}{ PP } & \multirow{3}{*}{$\begin{array}{c}\text { SP } \\
\text { Time } 8 \\
512 \pm 98\end{array}$} \\
\hline & \multirow{2}{*}{$\begin{array}{c}\text { Time } \mathbf{0} \\
536 \pm 105\end{array}$} & \multicolumn{2}{|c|}{ Time 1 (RM1) time 2} & \multirow{2}{*}{$\begin{array}{c}\text { Time } 3 \\
532 \pm 102\end{array}$} & \multicolumn{2}{|c|}{ Time 4 (RM2) time 5} & \multicolumn{2}{|c|}{ Time 6 (RM3) time 7} & \\
\hline & & $522 \pm 106.8$ & $534 \pm 102$ & & $511 \pm 99$ & $511 \pm 98.7$ & $512 \pm 97.8$ & $512 \pm 98.2$ & \\
\hline $\mathrm{RR}$, breaths/minute & $19 \pm 4.1$ & $19.5 \pm 4.1$ & $19.5 \pm 4.3$ & $19.5 \pm 4.3$ & $20 \pm 4.4$ & $20 \pm 4.4$ & $20 \pm 4.4$ & $20 \pm 4.4$ & $20 \pm 4.4$ \\
\hline$V^{\circ}, \mathrm{L} /$ minute & $10.5 \pm 2.3$ & $10.2 \pm 2$ & $10.4 \pm 2.2$ & $10.4 \pm 2.1$ & $10.2 \pm 2.2$ & $10.2 \pm 2.2$ & $10.2 \pm 2.2$ & $10.3 \pm 2.2$ & $10.3 \pm 2.2$ \\
\hline External PEEP, $\mathrm{cmH}_{2} \mathrm{O}$ & $9.8 \pm 2.8$ & $9.8 \pm 2.8$ & $9.8 \pm 2.8$ & $9.8 \pm 2.8$ & $10.1 \pm 2.6$ & $10.1 \pm 2.6$ & $10.1 \pm 2.6$ & $10.1 \pm 2.6$ & $10.3 \pm 2.7$ \\
\hline Total PEEP, $\mathrm{cmH}_{2} \mathrm{O}$ & $10.7 \pm 2.8$ & $10.6 \pm 2.8$ & $10.8 \pm 2.9$ & $10.8 \pm 2.7$ & $10.9 \pm 3$ & $11.4 \pm 3.3$ & $10.5 \pm 2.8$ & $10.6 \pm 2.9$ & $10.8 \pm 3$ \\
\hline Paw, $\mathrm{cmH}_{2} \mathrm{O}$ & $31.7 \pm 4.7$ & $30.5 \pm 6$ & $30.2 \pm 5.7$ & $31 \pm 4.9$ & $29 \pm 5.2$ & $30.5 \pm 5.2$ & $29 \pm 5.9$ & $28 \pm 5.3$ & $29 \pm 5.3$ \\
\hline Pplat, $\mathrm{CmH}_{2} \mathrm{O}$ & $24.6 \pm 5.8$ & $24.5 \pm 5.7$ & $24 \pm 5.5$ & $25.3 \pm 5^{b}$ & $24.2 \pm 4.6$ & $24 \pm 4.1$ & $23.4 \pm 4.9$ & $22.7 \pm 5^{c}$ & $23 \pm 5.1$ \\
\hline
\end{tabular}

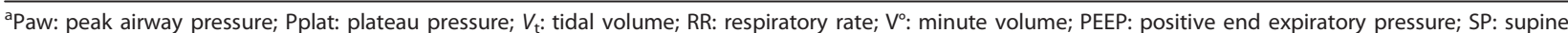
position; PP: prone position; RM recruitment maneuver. Ventilatory settings were measured each time (from time 0 to time 8 ) in SP and PP (see Figure 2):

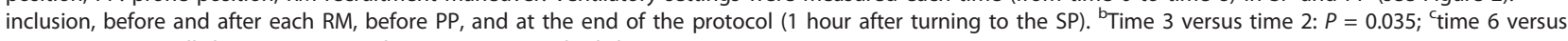
time 7: $P=0.02$. All data are expressed as means \pm standard deviations. 
Table 3 Gas exchanges used during the study ${ }^{a}$

\begin{tabular}{|c|c|c|c|c|c|c|c|c|c|}
\hline \multirow{3}{*}{$\frac{\text { Gas exchanges }}{\mathrm{pH}}$} & \multicolumn{4}{|c|}{ SP } & \multicolumn{4}{|c|}{ PP } & \multirow{3}{*}{$\begin{array}{c}\text { SP } \\
\text { Time 8 } \\
7.40 \pm 0.08^{f}\end{array}$} \\
\hline & \multirow{2}{*}{$\frac{\text { Time } 0}{7.37 \pm 0.08}$} & \multicolumn{2}{|c|}{ Time 1 (RM1) time 2} & \multirow{2}{*}{$\begin{array}{c}\text { Time } \mathbf{3} \\
7.36 \pm 0.08^{c}\end{array}$} & \multicolumn{2}{|c|}{ Time 4 (RM2) time 5} & \multicolumn{2}{|c|}{ Time 6 (RM3) time 7} & \\
\hline & & $7.37 \pm 0.07$ & $7.40 \pm 0.08^{b}$ & & $7.39 \pm 0.08$ & $7.43 \pm 0.08^{d}$ & $7.40 \pm 0.09$ & $7.47 \pm 0.08^{e}$ & \\
\hline $\mathrm{PaO}_{2}, \mathrm{mmHg}$ & $75.6 \pm 19$ & $85.4 \pm 28$ & $94.5 \pm 39$ & $88.9 \pm 24$ & $117 \pm 63$ & $138 \pm 77$ & $138.6 \pm 70$ & $171.5 \pm 84^{9}$ & $129.5 \pm 66^{h}$ \\
\hline $\mathrm{PaCO}_{2}, \mathrm{mmHg}$ & $39 \pm 7$ & $39 \pm 7.7$ & $35 \pm 7.4^{i}$ & $40 \pm 8.4^{j}$ & $37 \pm 8.4$ & $35 \pm 7.7^{\mathrm{k}}$ & $36.4 \pm 8.4$ & $31.5 \pm 8.4^{\prime}$ & $36.4 \pm 7.3^{m}$ \\
\hline $\mathrm{PaO}_{2} / \mathrm{FiO}_{2}$ ratio, $\mathrm{mmHg}$ & $98.3 \pm 28$ & $111.4 \pm 41.2$ & $123 \pm 52.3$ & $115.5 \pm 36$ & $151.2 \pm 75.7$ & $178 \pm 99$ & $177 \pm 75$ & $218.2 \pm 99.5^{n}$ & $165.6 \pm 84.5^{\circ}$ \\
\hline
\end{tabular}

${ }^{a} \mathrm{SP}$ : supine position; PP: prone position; $\mathrm{RM}$ : recruitment maneuver; $\mathrm{PaO}_{2}$ : arterial oxygen partial pressure; $\mathrm{PaCO}_{2}$ : arterial carbon dioxide partial pressure; PaO ${ }_{2} /$ $\mathrm{FiO}_{2}$ ratio, ratio of arterial oxygen partial pressure to fraction of inspired oxygen. Gas exchanges were measured each time (from time 0 to time 8 ) in SP and PP (see Figure 2): inclusion, before and after each RM, before PP and at the end of the protocol ( 1 hour after turning to the SP). ${ }^{\mathrm{b}} \mathrm{pH}$ time 2 versus time $1, P \leq 0.001$; ${ }^{\mathrm{c}} \mathrm{pH}$ time 3 versus time $2, P \leq 0.05 ;{ }^{\mathrm{d}} \mathrm{pH}$ time 5 versus time $4, P \leq 0.001 ;{ }^{\mathrm{e}} \mathrm{pH}$ time 7 versus time $6, P \leq 0.05 ;{ }^{\mathrm{f}} \mathrm{pH}$ time 8 versus time $7, P \leq 0.01 ;{ }^{9} \mathrm{PaO} \mathrm{O}_{2}$ time 7 versus time $6, P \leq 0.05 ;{ }^{h} \mathrm{PaO}_{2}$ time 8 versus time $0, P \leq 0.05 ;{ }^{\mathrm{i}} \mathrm{PaCO}_{2}$ time 2 versus time $1, P \leq 0.05 ;{ }^{\mathrm{j}} \mathrm{PaCO}{ }_{2}$ time 3 versus time $2, P \leq 0.05 ;{ }^{\mathrm{k}} \mathrm{PaCO}$ time 5 versus time 4, $P \leq 0.05) ;{ }^{I} \mathrm{PaCO}_{2}$ time 7 versus time $6, P \leq 0.05 ;{ }^{\mathrm{m}} \mathrm{PaCO}$ time 8 versus time $7, P \leq 0.01 ;{ }^{\mathrm{n}} \mathrm{PaO}_{2} / \mathrm{FiO}_{2}$ ratio time 7 versus time $6, P \leq 0.05 ;{ }^{\circ} \mathrm{PaO} \mathrm{O}_{2} / \mathrm{FiO}_{2}$ ratio time 8 versus time $0, P \leq 0.05$. All data are expressed as means \pm standard deviations.

RM in an animal model indicated that there were no protective effects against hyperinflation because of persistent lung inhomogeneity during the RM procedure [39]. A recent PP meta-analysis suggested a positive result on oxygenation and mortality and that VILI may be reduced or delayed during PP $[37,40,41]$. The combination of PP and RM may be a safe strategy to use for improvement of oxygenation and to avoid VILI. However, this strategy has not been studied often in the setting of acute respiratory failure [42-45].

In an oleic acid-induced lung injury model, Cakar et al. [42] studied the combination of PP and a $60 \mathrm{cmH}_{2} \mathrm{O}$ sustained inflation over 30 seconds. These authors observed greater oxygen improvement with reduced alveolar stress when PP was used. Three clinical studies in humans have tested the benefits of such a strategy. The findings of those studies are summarized in Table 4.

\section{Oxygenation efficacy}

Our study confirms the efficacy of RM in increasing $\mathrm{PaO}_{2}$ in SP and PP. The $\mathrm{PaO}_{2}$ improvement was transient in SP. In PP, the efficacy of RM performed after either one hour or six hours was different. First, $\mathrm{PaO}_{2}$

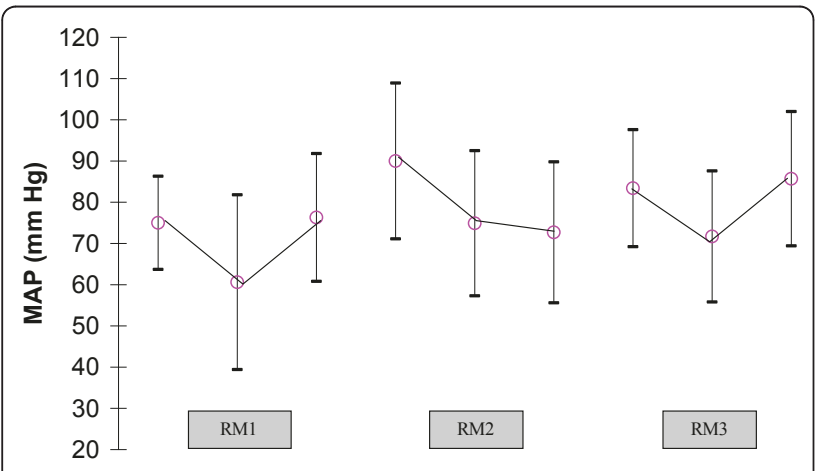

Figure 3 Changes in mean arterial pressure (MAP) during the three recruitment maneuvers showing significant decrease in MAP. RM1: $P=0.008 ; \mathrm{RM} 2: P=0.03 ; \mathrm{RM} 3: P=0.01$. did not decrease between the two RMs, and $\mathrm{PaO}_{2}$ changes were larger after the second RM. PP and RM may have a combined effect on $\mathrm{PaO}_{2}$, and this $\mathrm{PaO}_{2}$ improvement would be better if RM were used, probably at different times during PP and especially at the end of PP. A benefit on $\mathrm{PaO}_{2}$ was durable one hour after the end of PP. With an extended period of PP (more than 12 hours), the beneficial effect of RM while in PP remains to be demonstrated.

Pelosi et al. [43] and Oczenski et al. [44] demonstrated the efficacy of such a strategy. In Pelosi et al.'s study, sighs were used for one hour after two hours of PP. A positive $\mathrm{PaO}_{2}$ variation was found in SP and PP. In $\mathrm{SP}$ after $\mathrm{RM}, \mathrm{PaO}_{2}$ returned to the baseline, whereas in $\mathrm{PP}, \mathrm{PaO}_{2}$ remained higher than the baseline. In Oczenski et al.'s study, extended sigh was used at the end of the PP period, with a persistent increase in oxygenation while the patient was turned supine three hours later. Lim et al. [45] showed, first, with an extended sigh, an improvement in $\mathrm{PaO}_{2}$ in PP that was lower than in SP, and, second, a PEEP increase after RM prevented the after- $\mathrm{RM}$ decrease in $\mathrm{PaO}_{2} / \mathrm{FiO}_{2}$ ratio. The differences between oxygenation responses in SP and PP may be explained by two factors: Only the patients in the most severe condition with a $\mathrm{PaO}_{2} / \mathrm{FiO}_{2}$ ratio $<100$ were turned prone in the $\mathrm{PP}$ group, and the basic ventilation was delivered with an $8 \mathrm{~mL} / \mathrm{kg} V_{\mathrm{t}}$, which could have limited the extent of the effect of the RM [45].

\section{Recruitment manoeuvre strategy}

RM has been studied in experimental models and in clinical studies. An equivalent or superior efficacy of sigh or extended sigh has been demonstrated compared to continuous positive airway pressure (CPAP). In general, a 40 to $50 \mathrm{cmH}_{2} \mathrm{O}$ peak alveolar pressure is sufficient for lung recruitment $[46,47]$. The different RMs used in PP are summarized in Table 4 and included sigh, extended sigh and CPAP. They demonstrated a positive effect on alveolar recruitment and oxygenation 


\begin{tabular}{|c|c|c|c|c|c|c|c|c|c|c|}
\hline \multirow[b]{2}{*}{ Study } & \multirow[b]{2}{*}{$\begin{array}{l}\text { ARDS type, } \\
\text { number of } \\
\text { patients }\end{array}$} & & \multirow[b]{2}{*}{ RM type } & \multirow[b]{2}{*}{ Study design } \\
\hline & & $V_{\mathrm{t}}, \mathrm{mL}$ & $\begin{array}{c}\text { RR, } \\
\text { breaths/ } \\
\text { minute }\end{array}$ & $\begin{array}{l}\text { PEEP, } \\
\mathrm{cmH}_{2} \mathrm{O}\end{array}$ & $\begin{array}{l}\mathrm{PaO}_{2} / \mathrm{FiO}_{2} \\
\text { ratio, } \mathrm{mmHg}\end{array}$ & $\begin{array}{l}\text { Pplat, } \\
\mathrm{cmH}_{2} \mathrm{O}\end{array}$ & $\begin{array}{l}\mathrm{Pre}-\mathrm{PaO}_{2} / \\
\mathrm{FiO}_{2} \\
\text { ratio, } \\
\text { mmHg }\end{array}$ & $\begin{array}{l}\text { Post- } \\
\mathrm{PaO}_{2} / \mathrm{FiO}_{2} \\
\text { ratio, } \\
\mathrm{mmHg}\end{array}$ & & \\
\hline $\begin{array}{l}\text { Pelosi } \\
\text { et al., } 2003 \\
{[43]}\end{array}$ & $\begin{array}{l}\text { Early ARDS } \\
(n=10): 6 \\
\text { pulmonary, } 4 \\
\text { extrapulmonary }\end{array}$ & $\begin{array}{l}\text { About } 7 \\
\mathrm{~mL} / \mathrm{kg} \\
590 \mathrm{~mL}\end{array}$ & 14 & 14 & 121 & 32 & 193 & 240 & $\begin{array}{l}\text { Sigh: Three consecutive volume-limited } \\
\text { breaths/minute with a plateau pressure of } \\
45 \mathrm{cmH}_{2} \mathrm{O}\end{array}$ & $\begin{array}{l}\text { Following period of the study: } \\
\text { 2-hour baseline SP } \\
\text { 1-hour sigh SP } \\
\text { 1-hour baseline SP } \\
\text { 2-hour baseline PP } \\
\text { 1-hour sigh PP } \\
\text { 1-hour baseline PP } \\
\text { Measurements taken at end of each } \\
\text { period }\end{array}$ \\
\hline $\begin{array}{l}\text { Lim et al., } \\
2003 \\
{[45]}\end{array}$ & $\begin{array}{l}\text { Early ARDS } \\
(n=47): 37 \\
\text { pulmonary, } 10 \\
\text { extrapulmonary } \\
19 \text { patients } \\
\text { from a } \\
\text { preliminary } \\
\text { study }\end{array}$ & $\begin{array}{l}\text { About } 8 \\
\mathrm{~mL} / \mathrm{kg}\end{array}$ & 20 & 10 & 128 & - & 166 & 200 & $\begin{array}{l}\text { Extended sigh } \\
\text { Inflation phase: PEEP was increased by } 5 \\
\mathrm{CmH}_{2} \mathrm{O} \text { every } 30 \text { seconds with a } 2 \mathrm{~mL} / \mathrm{kg} \\
\text { decrease in } V_{\text {t. When PEEP reached } 25} \\
\mathrm{CmH}_{2} \mathrm{O} \text {, CPAP at } 30 \mathrm{cmH}_{2} \mathrm{O} \text { was used for } \\
30 \text { seconds. } \\
\text { Deflation phase }\end{array}$ & $\begin{array}{l}\text { Following period of the study: } \\
\text { Patients were randomised into two } \\
\text { arms: } \\
\text { (1) RM }+ \text { PEEP at } 15 \mathrm{cmH}_{2} \mathrm{O}(n=20) \text { or } \\
\text { (2) PEEP alone at } 15 \mathrm{CmH}_{2} \mathrm{O}(n=8) \text {. } \\
\text { A third arm of patients from a } \\
\text { preliminary study were analysed: RM } \\
\text { only }(n=19) \text {. } \\
\mathrm{PP} \text { was used only if } \mathrm{PaO}_{2} / \mathrm{FiO}_{2} \text { ratio } \\
\text { was }<100(n=14) \text {. The protocol } \\
\text { started after 2-hour PP. } \\
\text { Data were recorded before and after } \\
\text { RM }+\mathrm{PEEP} \text { (or PEEP only or RM only) } \\
\text { at } 15,30,45 \text { and } 60 \text { minutes after the } \\
\text { protocol. }\end{array}$ \\
\hline $\begin{array}{l}\text { Oczenski } \\
\text { et al., } 2005 \\
{[44]}\end{array}$ & $\begin{array}{l}\text { Early ARDS } \\
(n=15): \text { all } \\
\text { extrapulmonary }\end{array}$ & $\begin{array}{l}\text { About } 6 \\
\mathrm{~mL} / \mathrm{kg} \\
460 \text { to } 490 \\
\mathrm{~mL}\end{array}$ & 18 & 15 & 130 & 29 & 176 & 322 & CPAP: $50 \mathrm{cmH}_{2} \mathrm{O}$ for 30 seconds & $\begin{array}{l}\text { Following period of the study: } \\
\text { After } 6 \text {-hour PP period, RM was } \\
\text { performed. Data were recorded in SP } \\
\text { after } 6 \text { hours PP and 3, } 30 \text { and } 180 \\
\text { minutes after RM in SP. }\end{array}$ \\
\hline $\begin{array}{l}\text { Rival et al., } \\
2011 \\
\text { (present } \\
\text { study) }\end{array}$ & $\begin{array}{l}\text { Early ARDS } \\
(n=16): 12 \\
\text { pulmonary, } 4 \\
\text { extrapulmonary }\end{array}$ & $540 \mathrm{~mL}$ & 19 & 10 & 98 & 25 & 177 & 218 & $\begin{array}{l}\text { Extended sigh inflation phase: Pressure } \\
\text { levels } 30,35,40 \text { and } 45 \mathrm{CmH}_{2} \mathrm{O} \text { every } 30 \\
\text { seconds were used. At } 45 \mathrm{cmH}_{2} \mathrm{O} \text {, a } 30- \\
\text { second end inspiratory pause was } \\
\text { performed. } \\
\text { Deflation phase }\end{array}$ & $\begin{array}{l}\text { Following period of the study: } \\
\text { 6-hour SP with RM at beginning of SP. } \\
\text { Six-hour PP with two RM after } 1 \text { hour } \\
\text { and 6-hour PP. } \\
\text { Measurements taken at beginning of, } \\
\text { before and after each RM, and also at } \\
\text { end of each ventilation period and } 1 \\
\text { hour after end of protocol. }\end{array}$ \\
\hline
\end{tabular}

Best $\mathrm{PaO}_{2} / \mathrm{FiO}_{2}$ ratio

variation $(\mathrm{mmHg}), \mathrm{PP}$ $+\mathrm{RM}$

${ }^{a} \mathrm{ARDS}$ : acute respiratory distress syndrome; $V_{\mathrm{t}}$ : tidal volume; $\mathrm{RR}$ : respiratory rate; PEEP: positive end expiratory pressure; $\mathrm{PP}$ : prone position; $\mathrm{SP}$ : supine position; $\mathrm{RM}$ recruitment manoeuvre; $\mathrm{PaO} / \mathrm{FiO}{ }_{2}$ ratio, ratio of arterial oxygen partial pressure to fraction of inspired oxygen; Pplat: plateau pressure; CPAP, continuous positive airway pressure. 
in SP or PP. In our study, we practiced a RM using pressure control mode, and pressure was progressively increased in steps. The maximum pressure used was 45 $\mathrm{cmH}_{2} \mathrm{O}$. Compared with RMs described in literature, our method presents some sufficient features to open lung $[37,48]$ with a gradual increase of airway pressure during sufficient time to induce progressive alveolar recruitment and more homogeneous distribution of pressure throughout lung parenchyma. PEEP probably may be increased to stabilize alveolar recruitment and $\mathrm{PaO}_{2}$ in SP.

\section{Respiratory mechanics}

In the present study, plateau pressures and $\mathrm{PaCO}_{2}$ decreased throughout the PP period and after each RM. $\mathrm{PaCO}_{2}$ decreased from $39 \mathrm{mmHg}$ to $36.4 \mathrm{mmHg}$, and plateau pressure decreased from $24.6 \mathrm{cmH}_{2} \mathrm{O}$ to 23 $\mathrm{cmH}_{2} \mathrm{O}$. These results indirectly suggest changes in compliance and alveolar recruitment. Pelosi et al. [43] confirmed the benefit of such a ventilatory strategy: In their study, $\mathrm{PaCO}_{2}$ showed a decreasing pattern and end expiratory lung volume in PP was higher after RM than it was in SP $(277 \pm 198 \mathrm{~mL}$ vs. $68 \pm 83 \mathrm{~mL})$. Compliance followed the same improvement [43].

\section{Complications}

In our study, the protocol had to be interrupted once for arrhythmia and once for bronchoconstriction. Transient hypotension was noted, but MAP remained normal at the end of RM. In a systematic RM review, hypotension $(12 \%)$ and desaturation (9\%) were the most common adverse events. Serious adverse events (barotrauma and arrhythmia) were uncommon [49]. In an experimental model, a decrease in cardiac output was observed [50]. Nielsen et al. [51] tested the impact of $\mathrm{RM}$ in hypovolemia, normovolemia and hypervolemia. Lung RMs significantly decreased left ventricular end diastolic volume as well as cardiac output during hypovolemia. Caution should be taken, and volemia should be evaluated before starting a RM.

\section{Methodological considerations and limitations}

This study has several limitations. We are unable to argue for the long-lasting effect of the RM and PP combination on $\mathrm{PaO}_{2}$ and the benefit of such a strategy performed in all early ALI/ARDS groups. These questions require the enrolment of patients in a crossover study and follow-up of $\mathrm{PaO}_{2}$ while the patient is returned to SP. Such a study remains to be done. However, the response with regard to $\mathrm{PaO}_{2}$ is quite substantial and already has clinical significance. Because of the relatively small number of patients in our study, we were unable to sort patients according to the type of ARDS (lobar, patchy or diffuse ARDS).
The mechanisms of $\mathrm{PaO}_{2}$ improvement cannot be emphasized in our study. With the observed change in plateau pressure for a given $V_{\mathrm{t}}$, an increase in compliance and an improvement in residual capacity are likely. It would be interesting to measure alveolar recruitment and compliance. As the RM was considered part of daily care, Swan-Ganz catheterisation and cardiac ultrasonography were not systematically performed during the procedure. We do not have the data to analyse the transient haemodynamic instability which occurred during some RMs.

\section{Conclusions}

In clinical practice, and when RM may be used to improve $\mathrm{PaO}_{2}$ and decrease VILI, RM may be useful during PP and probably needs to be performed when the patient has been in PP for some time to obtain a full response. Whether a better response is obtained after a longer period of time in PP remains to be demonstrated. The pressure control mode used in our study was as efficient as other methods. However, the place of this strategy needs to be determined in ARDS patients who fail to respond to usual treatment so as not to delay the use of rescue treatments such as extracorporeal membrane oxygenation.

\section{Key messages}

- RM can be used in SP or PP to improve oxygenation.

- A pressure control mode was as efficient as other RMs.

- A probable combined effect on oxygenation exists between PP and RM.

- The combination of PP and RM may be assessed several times, preferably when the patient has been in PP for a few hours.

- No significant side effects were encountered in our study.

\section{Abbreviations}

ALI: acute lung injury; ARDS: acute respiratory distress syndrome; CPAP: continuous positive airway pressure; $\mathrm{FiO}_{2}$ : fraction of inspired oxygen; MAP: mean arterial pressure; $\mathrm{PaO}_{2}$ : arterial oxygen partial pressure; $\mathrm{PaO}_{2} / \mathrm{FiO}_{2}$ ratio: ratio of arterial oxygen partial pressure to fraction of inspired oxygen; $\mathrm{PaCO}_{2}$ : arterial carbon dioxide partial pressure; Paw: peak airway pressure; PEEP: positive end expiratory pressure; PIP: peak inspiratory pressure; PP: prone position; Pplat: plateau pressure; RM: recruitment manoeuvre; RR: respiratory rate; SAPS II: Simplified Acute Physiology Score II; SP: supine position; $V_{\mathrm{t}}$ : tidal volume.

\section{Acknowledgements}

The authors thank the physicians and nursing staff in the intensive care unit for their cooperation in the management of patients during the study. We are grateful to Melanie Cole and Delphine Roussely for their help in writing this article. This work was supported by Don du souffle.

\section{Author details}

${ }^{1}$ Service de pneumologie, Centre Hospitalier Régional et Universitaire de Besançon, 3 Bd Fleming, Besançon F-25000, France. ${ }^{2}$ Service de réanimation 
médicale, Centre Hospitalier Régional et Universitaire de Besançon, 3 Bd Fleming, Besançon F-25000, France. ${ }^{3}$ Département d'informatique médicale, Centre Hospitalier Régional et Universitaire Besançon, 3 Bd Fleming, Besançon F-25000, France. ${ }^{4}$ Equipe d'accueil EA 3920, Unité de Formation et de Recherche Médecine Pharmacie, Université de Franche Comté, 19 rue Ambroise Paré, les Hauts du Chazal Besançon F-25000 France.

\section{Authors' contributions}

GR and GC contributed to study conception and design. GR, GC, JCN, EB and CP contributed to patient recruitment into the study. GR contributed to the acquisition of data. NF contributed to the statistical analysis. All investigators commented on, critically revised and read and approved the final manuscript.

\section{Competing interests}

The authors declare that they have no competing interests.

Received: 22 January 2011 Revised: 20 April 2011

Accepted: 16 May 2011 Published: 16 May 2011

\section{References}

1. Bernard GR, Artigas A, Brigham KL, Carlet J, Falke K, Hudson L, Lamy L, Legall JR, Morris A, Spragg R: The American-European Consensus Conference on ARDS: definitions, mechanisms, relevant outcomes, and clinical trial coordination. Am J Respir Crit Care Med 1994, 149:818-824.

2. Dreyfuss D, Saumon G: Ventilator-induced lung injury: lessons from experimental studies. Am J Respir Crit Care Med 1998, 157:294-323.

3. Ricard JD, Dreyfuss D, Saumon G: Ventilator induced lung injury. Eur Respir J Supp/ 2003, 42:2s-9s.

4. Brochard L, Roudot-Thoraval F, Roupie E, Declaux C, Chastre J, FernandezMondéjar E, Clémenti E, Mancebo J, Matamis D, Ranieri M, Blanch L, Rodi G, Mentec H, Dreyfuss D, Ferrer M, Brun-Buisson C, Tobin M, Lemaire F: Tidal volume reduction for prevention of ventilation-induced lung injury in acute respiratory distress syndrome. Am J Respir Crit Care Med 1998, 158:1831-1838.

5. The Acute Respiratory Distress Syndrome Network: Ventilation with lower tidal volumes as compared with traditional tidal volumes for acute lung injury and the acute respiratory distress syndrome. N Engl I Med 2000, 342:1301-1308.

6. Putensen C, Theuerkauf N, Zinserling J, Wrigge H, Pelosi P: Meta-analysis: ventilation strategies and outcomes of the acute respiratory distress syndrome and acute lung injury. Ann Intern Med 2009, 151:566-576, Erratum: Ann Intern Med 2009, 151: 897.

7. Hubmayr RD: Perspective on lung injury and recruitment: a skeptical look at the opening and collapse story. Am J Respir Crit Care Med 2002, 165:1647-1653.

8. Richard JC, Maggiore SM, Jonson B, Mancebo J, Lemaire F, Brochard L: Influence of tidal volume on alveolar recruitment: respective role of PEEP and a recruitment maneuver. Am J Respir Crit Care Med 2001, 163:1609-1613.

9. Lapinsky S, Mehta S: Bench-to-bedside review: recruitment and recruiting maneuvers. Crit Care 2005, 9:60-65.

10. Caironi P, Cressoni M, Chiumello D, Ranieri M, Quintel M, Russo S, Cornejo R, Bugedo G, Carlesso E, Russo R, Caspani L, Gattinoni L: Lung opening and closing during ventilation of acute respiratory distress syndrome. Am J Respir Crit Care Med 2010, 181:578-586.

11. Suárez-Sipmann F, Böhm S, Lachmann B: Clinical perspectives of "the open lung concept.". Minerva Anestesiol 1999, 65:310-312.

12. Kacmarek RM, Schwartz DR: Lung recruitment. Respir Care Clin N Am 2000, 6:597-623.

13. Kacmarek RM: Strategies to optimize alveolar recruitment. Curr Opin Crit Care 2001, 7:15-20.

14. Papadakos PJ, Lachmann B: The open lung concept of alveolar recruitment can improve outcome in respiratory failure and ARDS. Mt Sinai J Med 2002, 69:73-77.

15. Hess DR, Bigatello LM: Lung recruitment: the role of recruitment maneuvers. Respir Care 2002, 47:308-317.

16. Kacmarek RM, Kallet RH: Should recruitment maneuvers be used in the management of ALI and ARDS? Respir Care 2007, 52:622-631.
17. Rimensberger PC, Cox PN, Frndova H, Bryan AC: The open lung during small tidal volume ventilation: concepts of recruitment and "optimal" positive end-expiratory pressure. Crit Care Med 1999, 27:1946-1952.

18. Hickling K: Low tidal volume ventilation: a PEEP at the mechanisms of derecruitment. Crit Care Med 2003, 31:318-320.

19. Halter J, Steinberg J, Schiller H, DaSilva M, Gatto M, Landas S, Nieman G: Positive end expiratory pressure after a recruitment maneuver prevents both alveolar collapse and recruitment/derecruitment. Am J Respir Crit Care Med 2003, 167:1620-1626.

20. Giris K, Hamed H, Khater $Y$, Kacmarek R: A decremental PEEP trial identifies the PEEP level that maintains oxygenation after lung recruitment. Respir Care 2006, 51:1132-1139.

21. Mercat A, Richard JC, Vielle B, Jaber S, Osman D, Diehl JL, Lefrant JY, Prat G, Richecoeur J, Nieszkowska A, Gervais C, Baudot J, Bouadma L, Brochard L, Expiratory Pressure Study (Express) Group: Acute lung injury and acute respiratory distress positive end-expiratory pressure setting in adults with syndrome: a randomized controlled trial. JAMA 2008, 299:646-655.

22. Fanelli V, Mascia L, Puntorieri V, Assenzio B, Elia V, Fornaro G, Martin EL, Bosco M, Delsedime L, Fiore T, Grasso S, Ranieri M: Pulmonary atelectasis during low stretch ventilation: "open lung" versus "lung rest" strategy. Crit Care Med 2009, 37:1046-1053.

23. Guerin C, Badet M, Rosselli S, Heyer L, Sab JM, Langevin B, Philit F, Fournier G, Robert D: Effects of prone position on alveolar recruitment and oxygenation in acute lung injury. Intensive Care Med 1999, 25:1222-1230.

24. Gattinoni L, Tognoni G, Pesenti A, Taccone P, Mascheroni D, Labarta V, Malacrida R, Di Giulio P, Fumagalli R, Pelosi P, Brazzi L, Latini R, ProneSupine Study Group: Effect of prone positioning on the survival of patients with acute respiratory failure. N Engl J Med 2001, 345:568-573.

25. Pelosi P, Caironi P, Taccone P, Brazzi L: Pathophysiology of prone positioning in the healthy lung and in ALL/ARDS. Minerva Anestesiol 2001, 67:238-247.

26. Mackenzie CF: Anatomy, physiology, and pathology of the prone position and postural drainage. Crit Care Med 2001, 29:1084-1085.

27. Lapinsky SE, Aubin M, Mehta S, Boiteau P, Slutsky AS: Safety and efficacy of a sustained inflation for alveolar recruitment in adults with respiratory failure. Intensive Care Med 1999, 25:1297-1301.

28. Grasso S, Puntillo F, Mascia L, Cafarelli A, Trotta T, Capobianco G, Ancona G, Bruno F, Slutsky A, Ranieri VM: Volume recruiting maneuver (VRM) in ARDS patients. Am J Respir Crit Care Med 1999, 159:1172-1178.

29. Lapinsky SE, Aubin M, Mehta S, Boiteau P, Slutsky AS: Safety and efficacy of a sustained inflation for alveolar recruitment in adults with respiratory failure. Intensive Care Med 1999, 25:1297-1301.

30. Pelosi P, Cadringher P, Bottino N, Panigada M, Carrieri F, Riva E, Lissoni A, Gattinoni L: Sigh in acute respiratory distress syndrome. Am J Respir Crit Care Med 1999, 159:872-880.

31. Foti G, Cereda M, Sparacino ME, De Marchi L, Villa F, Pesenti A: Effects of periodic lung recruitment maneuvers on gas exchange and respiratory mechanics in mechanically ventilated acute respiratory distress syndrome (ARDS) patients. Intensive Care Med 2000, 26:501-507.

32. Richards $G$, White H, Hopley M: Rapid reduction of oxygenation index by employment of recruitment technique in patients with severe ARDS. Intensive Care Med 2001, 16:193-199.

33. Crotti S, Mascheroni D, Caironi P, Pelosi P, Ronzoni G, Mondino M, Marini JJ, Gattinoni L: Recruitment and derecruitment during acute respiratory failure: a clinical study. Am J Respir Crit Care Med 2001, 164:131-140.

34. Grasso S, Mascia L, Del Turco M, Malacarne P, Giunta F, Brochard L, Slutsky AS, Ranieri VM: Effects of recruiting maneuvers in patients with acute respiratory distress syndrome ventilated with protective ventilatory strategy. Anesthesiology 2002, 96:795-802.

35. Constantin JM, Jaber S, Futier E, Cayot-Constantin S, Verny-Pic M, Jung B, Bailly A, Guerrin R, Bazin JE: Respiratory effects of different recruitment maneuvers in acute respiratory distress syndrome. Crit Care 2008, 12:R50.

36. Badet M, Bayle F, Richard JC, Guerin C: Comparison of optimal positive end-expiratory pressure and recruitment maneuvers during lungprotective mechanical ventilation in patients with acute lung injury/ acute respiratory distress syndrome. Respir Care 2009, 54:847-854.

37. Pelosi P, Gama de Abreu M, Rocco P: New and conventional strategies for lung recruitment in acute respiratory distress syndrome. Crit Care 2010, 14:210-216. 
38. Kacmarek $R$, Villar J: Lung recruitment maneuvers during respiratory distress syndrome: is it useful? Minerva Anestesiol 2011, 77:85-89.

39. Grasso S, Stripoli T, Sacchi M, Trerotoli P, Staffieri F, Franchini D, De Monte V, Valentini V, Pugliese P, Crovace A, Driessen B, Fiore T: Inhomogeneity of lung parenchyma during the open lung strategy: a computed tomography scan study. Am J Respir Crit Care Med 2009, 180:415-423.

40. Gattinoni L, Carlesso E, Taccone P, Polli F, Guérin C, Mancebo J: Prone positioning improves survival in severe ARDS: a pathophysiological review and individual patient meta-analysis. Minerva Anestesiol 2010, 76:448-454.

41. Abroug F, Ouanes-Besbes L, Dachraoui F, Ouanes I, Brochard L: An updated study-level meta-analysis of randomised controlled trials on proning in ARDS and acute lung injury. Crit Care 2011, 15:R6.

42. Cakar N, Van der Kloot T, Youngblood M, Adams A, Nahum A: Oxygenation response to a recruitment maneuver during supine and prone positions in an oleic acid-induced lung injury model. Am J Respir Crit Care Med 2000, 161:1949-1956.

43. Pelosi P, Bottino N, Chiumello D, Caironi P, Panigada M, Gamberoni C, Colombo G, Bigatello LM, Gattinoni L: Sigh in supine and prone position during acute respiratory distress syndrome. Am J Respir Crit Care Med 2003, 167:521-527.

44. Oczenski W, Hörmann C, Keller C, Lorenzl N, Kepka A, Schwarz S, Fitzgerald R: Recruitment maneuvers during prone positioning in patients with acute respiratory distress syndrome. Crit Care Med 2005, 33:54-61.

45. Lim CM, Jung H, Koh Y, Lee JS, Shim TS, Lee SD, Shim TS, Lee SD, Kim WS, Kim DS, Kim WD: Effect of alveolar recruitment maneuver in early acute respiratory distress syndrome according to antiderecruitment strategy, etiological category of diffuse lung injury, and body position of the patient. Crit Care Med 2003, 31:411-418.

46. Lim SC, Adams AB, Simonson DA, Dries DJ, Broccard AF, Hotchkiss JR, Marini JJ: Intercomparison of recruitment maneuver efficacy in three models of acute lung injury. Crit Care Med 2004, 32:2371-2377.

47. lanuzzi M, De Sio A, De Robertis E, Piazza O, Servillo G, Tuffano R: Different patterns of lung recruitment maneuvers in primary acute respiratory distress syndrome: effects on oxygenation and central hemodynamics. Minerva Anestesiol 2010, 76:692-698.

48. Albert S, DiRocco J, Gilman A, Bates J, Lafollette R, Kubiak B, Fischer J, Maroney S, Nieman G: The role of time and pressure on alveolar recruitment. J Appl Physiol 2009, 106:757-765.

49. Fan E, Wilcow ME, Brower R, Steward T, Mehta S, Lapinsky S, Meade M, Ferguson N: Recruitment maneuvers for acute lung injury: a systematic review. Am J Respir Crit Care Med 2008, 178:1156-1163.

50. Lim SC, Adams AB, Simonson DA, Dries DJ, Broccard AF, Hotchkiss JR, Marini JJ: Transient hemodynamic effects of recruitment maneuvers in three experimental models of acute lung injury. Crit Care Med 2004 32:2378-2384.

51. Nielsen J, Nilsson M, Fredén F, Hultman J, Alström U, Kjærgaard J, Hedenstierna G, Larsson A: Central hemodynamics during lung recruitment maneuvers at hypovolemia, normovolemia and hypervolemia: a study by echocardiography and continuous pulmonary artery flow measurements in lung-injured pigs. Intensive Care Med 2006, 32:585-594.

\section{Submit your next manuscript to BioMed Central and take full advantage of:}

- Convenient online submission

- Thorough peer review

- No space constraints or color figure charges

- Immediate publication on acceptance

- Inclusion in PubMed, CAS, Scopus and Google Scholar

- Research which is freely available for redistribution

Submit your manuscript at www.biomedcentral.com/submit
Biomed Central 